\title{
RESISTÊNCIA À VERMINOSE E SUPLEMENTAÇÃO PROTEICA NO PERIPARTO: EFEITO NO PARASITISMO E NO DESEMPENHO REPRODUTIVO DE OVELHAS DO GRUPAMENTO RACIAL PANTANEIRO
}

\author{
WORM RESISTANCE AND PROTEIN SUPPLEMENTATION IN \\ PERIPARTUM: EFFECT ON PARASITISM AND REPRODUCTIVE \\ PERFORMANCE OF SHEEP FROM PANTANEIRO BREED GROUP
}

\author{
Luis Henrique Fernandes ${ }^{1}$ \\ João Batista Catto ${ }^{1^{*}}$ \\ Fernando Alvarenga Reis ${ }^{1}$ \\ Gelson Luis Dias Feijó ${ }^{1}$ \\ Nilton Gabriel Paiva Guimarães ${ }^{1}$ \\ Jose Alexandre Agiova da Costa ${ }^{1}$ \\ ${ }^{1}$ Centro Nacional de Pesquisa em Gado de Corte - EMBRAPA, Campo Grande, MS, Brasil. \\ *Autor para correspondência - joao.catto@embrapa.br
}

\section{Resumo}

Os objetivos do trabalho foram avaliar o efeito do grau de resistência à verminose e da suplementação proteica nos índices reprodutivos e no parasitismo em ovelhas do grupamento racial Pantaneiro. As ovelhas foram classificadas pelo número de ovos de nematodas por grama de fezes (OPG) como resistentes (RR), sensíveis (SS) e intermediárias (RS), e submetidas (SUPL) ou não (NSUPL) à suplementação durante o terço final da gestação e na lactação. Em dois ciclos reprodutivos, a cada 28 dias, as ovelhas foram pesadas e tratadas com anti-helmínticos quando o OPG apresentava-se $\geq 4000$. O peso das ovelhas não foi influenciado pelo grau de resistência aos nematódeos e a suplementação teve efeito no peso somente no período em que foi ofertada. As taxas de natalidade e de desmame não foram influenciadas pelo grau de resistência e pela suplementação. A taxa de mortalidade de crias foi menor no grupo SUPL. A taxa de mortalidade de ovelhas foi três vezes mais elevada no grupo SS em relação ao grupo RR e o peso das crias foi menor no grupo SS em relação aos grupos RR e RS. Os três grupos mostraram picos no OPG durante o terço final da gestação, mas as médias foram sempre menores no grupo RR que, no geral, necessitaram 2,5 vezes menos tratamentos anti-helmínticos que as SS. A suplementação não apresentou correlação com o OPG e com o número de tratamentos anti-helmínticos. A classificação de ovelhas pelo OPG em resistentes aos nematodas proporcionou menor número de tratamentos antihelmínticos, menor taxa de mortalidade de ovelhas e peso maior das crias ao nascimento. 
Palavras-chave: índices produtivos; ganho de peso; nematódeos gastrintestinais; ovinos pantaneiros.

\begin{abstract}
The objectives of this study were to evaluate the effect of the level of worm resistance and protein supplementation on reproductive performance and parasitism in Pantaneiro sheep. Sheep were classified by the number of nematode eggs per gram of feces (EPG) as resistant (RR), sensitive (SS), and intermediate (RS), as well as submitted (SUPL) or not (NSUPL) to supplementation during the final third of pregnancy and lactation. In both reproductive cycles, sheep were weighed every 28 days and treated with anthelmintic when EPG was $\geq 4000$. The weight of the sheep was not affected by the degree of resistance to nematodes and supplementation only affected weight in the period in which it was offered. Birth and weaning rates were not affected by the degree of resistance and supplementation. Offspring mortality rate was lower in the SUPL group. Sheep mortality rate was three times higher in the SS group than in the RR group and offspring weight was lower in the SS group than in RR and RS groups. The three groups showed peaks in EPG during the final third of pregnancy; however, the averages were always lower in the RR group, which, in general, required 2.5 times less anthelmintic treatments than SS group. Supplementation had no effect on EPG and on the number of anthelmintic treatments. The classification of sheep as resistant to nematodes by EPG led to fewer anthelmintic treatments, lower sheep mortality rate and higher birth weight of offspring. Keywords: gastrointestinal nematodes; pantaneiro sheep; productivity indexes; weight gain.
\end{abstract}

Recebido em: 03 junho de 2016

Aceito em: 31 julho de 2017

\title{
Introdução
}

A criação de ovinos no Mato Grosso do Sul até recentemente era caracterizada por pequenos rebanhos de animais crioulos com a finalidade de produzir carne e artigos de montaria para consumo na propriedade $^{(1)}$. Historicamente, a criação voltada para essa finalidade era particularmente realizada no Pantanal devido ao isolamento da região.

Com a demanda crescente por carne de cordeiros no Brasil, está havendo um aumento significativo de criação de ovinos no Mato Grosso do Sul. Contudo, sistemas voltados para a produção de cordeiros na região são recentes. Além disso, informações sobre raças e cruzamentos, estratégias de reprodução e alimentação, terminação e controle sanitário ainda necessitam de validações técnicas e econômicas. A eficiência reprodutiva em ovinos é, em última instância, avaliada pela taxa de desmame e a obtenção de altos índices reprodutivos depende de vários fatores, entre os quais a precocidade, longevidade reprodutiva, frequência de parições, prolificidade e taxa de sobrevivência de $\operatorname{cordeiros}^{(2)}$.

As parasitoses gastrintestinais, especialmente a hemoncose, são consideradas o principal problema sanitário pelos prejuízos causados pela perda de peso, mortalidade elevada e baixas taxas de natalidade e de desmame. No Mato Grosso do Sul, a verminose também é percebida como a principal doença, agravada pela disseminação da resistência dos parasitas aos anti-helmínticos ${ }^{(3)}$. 
O uso de animais ou raças resistentes pode, alternativamente, melhorar o desempenho dos rebanhos ${ }^{(4-5)}$. O desenvolvimento de linhagens de ovinos resistentes às verminoses pela reprodução seletiva tem sido utilizado na Austrália e Nova Zelândia. Investigação de campo, contudo, tem resultado tanto em relações favoráveis quanto desfavoráveis entre as características de produção e maior resistência aos parasitas $^{(6-8)}$. O desenvolvimento de uma resposta imune competente contra os nematodas está associado negativamente com a eficiência nutricional como anorexia e mudanças nas rotas metabólicas, que são questões levantadas quando se busca o fortalecimento da resposta imune pela seleção genética ${ }^{(9)}$.

Os ovinos crioulos denominados Pantaneiros ${ }^{(10)}$ são oriundos de cruzamentos entre raças trazidas pelos colonizadores que apresentam combinação de alelos indicando aproximação das raças lanadas do Sul, como a Crioula, e deslanadas do Nordeste ${ }^{(11)}$. São encontrados em fazendas mais isoladas da região, sem nenhum controle reprodutivo ou sanitário e em processo de seleção natural ${ }^{(12)}$. Esta adaptação é evidenciada em algumas características, como pouca ou nenhuma lã nas pernas, barriga e pescoço; porte pequeno a médio, refletindo menor necessidade de mantença nas condições do Pantanal; não apresentam sazonalidade reprodutiva e tanto machos como fêmeas são precoces sexualmente $e^{(13)}$.

Os objetivos deste trabalho foram avaliar o efeito do grau de resistência à verminose e da suplementação proteica durante o periparto-lactação sobre o parasitismo e nos índices zootécnicos de um rebanho de matrizes predominantemente do grupamento racial Pantaneiro, no estado de Mato Grosso do Sul.

\section{Material e Métodos}

O experimento foi realizado no campo experimental Fazenda Modelo da EMBRAPA Gado de Corte, Município de Terenos, MS, Brasil (Coordenadas 2055’S; 5481’W). O clima da região, segundo a classificação de Köppen, situa-se na faixa de transição entre o sub-tipo Cfa-mesotérmico úmido sem estiagem e o sub-tipo Aw - tropical úmido com estação chuvosa no verão e seca no inverno. Aproximadamente $75 \%$ da precipitação anual média de $1400 \mathrm{~mm}^{3}$ ocorre entre os meses de outubro e abril, com temperatura média em torno de $24^{\circ} \mathrm{C}$. Os meses de menor precipitação são junho, julho e agosto, com médias mensais menores que $40 \mathrm{~mm}$ e temperatura média de $21^{\circ} \mathrm{C}$.

A fase experimental, com dois ciclos reprodutivos, foi precedida por um período de cinco meses em que 270 ovelhas vazias, multíparas, adquiridas de várias propriedades no Pantanal Sul-matogrossense, foram mantidas em uma mesma pastagem sem tratamento anti-helmíntico e submetidas mensalmente a exames de fezes para estimar o número de ovos de nematodas (OPG). Foram ranqueadas pela média de OPG e classificadas em três grupos com 60 animais como Sensíveis (SS), Intermediárias (RS) e Resistentes (RR) considerando também o peso médio corporal e a proporcionalidade nos fenótipos raciais. Fenotipicamente, foram caracterizadas como sendo 57\% ovelhas do grupo genético Pantaneiro, 14,5\% mestiços Pantaneiros x Suffolk, 14,5\% Pantaneiros x Texel, 5,5\% Pantaneiros x Bergamácia e 8,5\% outros mestiços.

A área experimental constituiu-se de 14,4 ha de Brachiaria brizantha cv Marandu, dividida em seis 
piquetes de 2,4 ha, com lotação de 12,5 ovelhas/ha, em sistema de pastejo contínuo. Disponibilizouse para cada grupo uma área central coberta, provida de bebedouro e sal mineral (níveis de garantia/kg do produto: cobre $350 \mathrm{mg}$; cromo 11,70 mg; enxofre 11,70 g; ferro $700 \mathrm{mg}$; flúor (máx.) $600 \mathrm{mg}$; fósforo 60 g; iodo 50 mg; manganês 1.200 mg; molibdênio 180 mg; selênio 15 mg; sódio 132 g; zinco $2.600 \mathrm{mg})$.

O cio das ovelhas foi sincronizado por meio da utilização de dispositivo intravaginal de progesterona e posterior aplicação de gonadotrofina coriônica equina como indutor da ovulação, seguindo o Protocolo Longo de Sincronização de Cio em Caprinos e Ovinos ${ }^{(14)}$. Seis reprodutores do grupo racial Pantaneiro foram usados na cobertura das matrizes. Para evitar o efeito paterno, seis lotes foram formados com cinco ovelhas de cada grupo, totalizando 30 ovelhas/lote. Em cada lote foi utilizado um macho em monta natural por três dias e, após 10 dias, permaneceram com as ovelhas por mais um período de 14 dias.

A tosquia e a sincronização do cio foram realizadas em setembro e outubro/novembro no primeiro ciclo e em novembro e dezembro no segundo ciclo. Os nascimentos ocorreram entre 28/03 e 25/04 de 2011, no primeiro ciclo, e entre 03/05 e 08/06 de 2012, no segundo ciclo. As crias foram pesadas pela manhã, numeradas e a profilaxia do umbigo foi realizada. As ovelhas foram everminadas no inicio do primeiro ciclo e vacinadas contra clostridioses anualmente. Foram pesadas a cada 28 dias e amostras fecais tomadas diretamente do reto para determinar número de ovos por grama de fezes (OPG) de acordo com Gordon \& Whitlock ${ }^{(15)}$, recebendo tratamento anti-helmíntico quando o OPG era $\geq 4000$, conforme Amarante ${ }^{(16)}$. Para registro da variação de peso corporal das ovelhas, foram consideradas as pesagens no início do experimento (PI), na estação de monta (PM), a última pesagem antes do parto (PP) e no desmame (PD).

Os três grupos selecionados quanto à resistência foram subdivididos, ao acaso, em dois: suplementados (SUPL) e não suplementados (NSUPL). Baseado em estimativas de disponibilidade de matéria seca (MS) e níveis de proteína para Braquiaria brizantha na região, da época do ano, estágio reprodutivo e exigências nutricionais para ovelhas de $50 \mathrm{~kg}^{(17)}$, a dieta deveria suprir as exigências de proteína do grupo SUPL durante todo o ciclo, enquanto as do grupo NSUPL teriam deficiência de proteína no final da gestação e lactação. No primeiro ciclo (maio de 2010 a junho de 2011), durante a estação seca e até a monta em novembro, todos os grupos receberam 1,7 kg/cabeça dia de silagem de sorgo. De setembro até março, as ovelhas dos grupos SUPL receberam $40 \mathrm{~g} /$ cabeça/dia de sal proteinado (mistura mineral para ovinos 20\%; sal branco 20\%; uréia 20\%; milho moído $20 \%$ e farelo de soja 15\%) e a partir de 01/04/2011 receberam 140 gramas ( $\pm 0,37 \%$ do peso vivo) cabeça/dia de concentrado energético-proteico até o desmame (mistura mineral para ovinos 9,2\%; uréia 9\%; milho moído 14\%; farelo de soja 66\% e sulfato de amônia 1,8\%).

No segundo ciclo (agosto de 2011 a julho de 2012), devido a episódios de predação por Puma concolor, os grupos foram temporariamente desfeitos para permitir o recolhimento noturno dos animais. Com a construção de telados para evitar a predação, os lotes SUPL receberam, a partir do terço final da gestação até o desmame, 250 g ( $\pm 0,67 \%$ peso vivo) cabeça/dia de concentrado energético-proteico com $17 \%$ de PB e $85,2 \%$ de NDT. Devido ao número elevado de mortes de ovelhas durante o periparto, o grupo NSUPL passou também a receber 250 g/cabeça/dia de ração até o desmame. Do início de julho até o desmame, os animais de todos os grupos receberam 1,7 $\mathrm{kg} /$ cabeça/dia de silagem de sorgo. 
O delineamento foi um fatorial 3 x 2 com três níveis de resistência e dois de suplementação. Os dados de peso corporal das ovelhas foram analisados em um modelo contendo os efeitos de grau de resistência (RR, RS, SS), da suplementação (SUPL e NSUPL), do ano de coleta (1 ou 2) e da interação entre ano e suplementação. Não houve interação entre suplementação e grau de resistência que, portanto, não foi considerada no modelo. O mesmo modelo foi utilizado para a análise do peso ao nascimento dos cordeiros, porém sem considerar o efeito da interação entre suplementação e ano. Os resultados das contagens de OPG foram transformados em log10(opg+1); contudo, as médias de OPG estão apresentadas não transformadas para facilitar a comparação das contagens. A análise estatística foi realizada por meio da análise de variância, utilizando-se o procedimento GLM do SAS (Version 9.3), e as médias ajustadas dos tratamentos comparadas pelo teste de Tukey a 5\%. As taxas de natalidade, mortalidade e desmame foram comparados por testes de Qui-quadrado ou exato de Fischer.

\section{Resultados e Discussão}

A taxa de natalidade média de 83,2\% observada nas 180 ovelhas experimentais foi superior às obtidas para as raças Santa Inês e Morada Nova, 76,2\% e 74,4\%, respectivamente ${ }^{(18)}$, semelhante à observada em ovelhas SRD, 82,8\% ${ }^{(19)}$, e inferior à obtida em ovelhas Santa Inês de 86,8 a 89,6\% ${ }^{(20)}$.

Observaram-se 13,1\% de partos duplos. As taxas médias de mortalidade nas crias de parto simples e duplos foram de de $14,6 \%$, e $32,1 \%$, respectivamente, próximas às taxas de $11 \%$ e $31 \%$ obtidas por Figueiredo $^{(21)}$ e de $16,3 \%$ e $25,7 \%$ encontradas por Costa ${ }^{(22)}$ em ovelhas Morada Nova, e inferiores às taxas de $26,6 \%$ e $48 \%$ observadas por Moura ${ }^{(20)}$ em ovelhas Santa Inês.

O peso das crias ao nascimento (PCN) (Tabela 2) foi inferior aos 3,70 obtido em crias de Santa Inês ${ }^{(23)}$ e superior aos $2,81 \mathrm{~kg}^{(24)}$ e 2,90 $\mathrm{kg}^{(25)}$ verificados em crias de ovelhas Somalis no Nordeste. O tipo

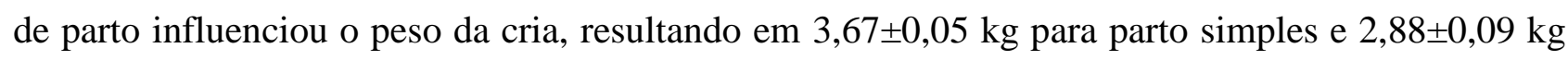
para parto duplo, também observado por Pinheiro ${ }^{(26)}$ em crias Santa Inês com 3,94 kg nos partos simples e 3,39 kg nos duplos.

A suplementação teve efeito $(\mathrm{P}<0,05)$ no peso corporal das ovelhas ao parto $(\mathrm{PP})$, em média com 2 kg a mais (Tabela 1). O ano influenciou a variação de peso corporal no PM e no PD, com valor médio de $4 \mathrm{~kg}$ a menos no segundo ciclo $(\mathrm{P}<0,05)$ (Tabela 1$)$. Entre o parto e o desmame, todos os grupos perderam aproximadamente $9 \mathrm{~kg}, 24 \%$ do peso vivo (Tabela 1). No primeiro ciclo, a lactação ocorreu entre abril e junho e no segundo, entre maio e julho, período de transição de chuvas para seca, quando há queda na disponibilidade e na qualidade da pastagem.

Em relação aos índices reprodutivos, a suplementação proteica teve efeito apenas na taxa de mortalidade de crias (Tabela 2). Silva et al. ${ }^{(27)}$ observaram diferença no peso e ausência de efeito nos índices reprodutivos em ovelhas SRD suplementadas com $270 \mathrm{~g} /$ dia com ração à base de milho e torta de algodão, durante a gestação e lactação. Não foi encontrado efeito no peso e nos índices reprodutivos de ovelhas Santa Inês suplementadas com fécula de mandioca e casca de grão de soja ${ }^{(23)}$ e de ovelhas Hampshire Down e Ile de France recebendo 250 gramas de uma mistura contendo milho triturado e farelo de soja ${ }^{(28)}$. 
Tabela 1. Variação média do peso corporal $(\mathrm{kg})$ entre o peso inicial e a monta (PI ao PM), entre a monta e o parto (PM ao PP) e entre o parto e o desmame (PP ao PD) em ovelhas sensiveis (SS), intermediárias (RS) e resistentes (RR) aos nematodas gastrintestinais, suplementadas (SUPL) e não suplementadas (NSUPL) no Mato Grosso do Sul

\begin{tabular}{lccc}
\hline & PI ao PM & PM ao PP & PP ao PD \\
\hline SS & $3,27 \pm 0,40^{\text {ab }}$ & $7,44 \pm 0,54$ & $-9,81 \pm 0,63$ \\
RS & $4,02 \pm 0,38^{\mathrm{a}}$ & $6,28 \pm 0,51$ & $-8,77 \pm 0,61$ \\
RR & $2,39 \pm 0,40^{\mathrm{b}}$ & $7,52 \pm 0,54$ & $-9,60 \pm 0,65$ \\
SUPL & - & $8,17 \pm 0,41^{\mathrm{a}}$ & $-9,55 \pm 0,49$ \\
NSUPL & - & $5,98 \pm 0,46^{\mathrm{b}}$ & $-9,23 \pm 0,55$ \\
Ano 1 & $4,72 \pm 0,29^{\mathrm{a}}$ & $7,25 \pm 0,39$ & $-11,13 \pm 0,48^{\mathrm{a}}$ \\
Ano 2 & $1,73 \pm 0,36^{\mathrm{b}}$ & $6,90 \pm 0,48$ & $-7,65 \pm 0,56^{\mathrm{b}}$ \\
\hline
\end{tabular}

Letras diferentes na coluna, para cada efeito, indica diferença significativa $(P<0,05)$.

Tabela 2. Taxa média de natalidade, de desmame e de mortalidade de ovelhas e de mortalidade e peso de cordeiros ao nascimento para ovelhas selecionadas como sensiveis (SS), intermediarias (RS) e resistentes (RR) aos nematodas gastrintestinais e suplementadas (SUPL) ou não (NSUPL) no Mato Grosso do Sul

\begin{tabular}{lccccc}
\hline \multicolumn{1}{c}{ Indices Zootécnicos } & SS & RS & RR & SUPL & NSUPL \\
\hline Fertilidade (\%) $^{1}$ & 87,1 & 78,4 & 85,7 & - & - \\
Prolificidade & 1,142 & 1,081 & 1,150 & 1,126 & 1,126 \\
Desmame (\%) & 63,4 & 71,6 & 70,4 & 74,2 & 62,7 \\
Mortalidade ovelhas (\%) & $20,8^{\mathrm{a}}$ & $12,7^{\mathrm{ab}}$ & $6,1^{\mathrm{b}}$ & 11,3 & 15,3 \\
Mortalidade ovelhas no periparto (\%) & 16,8 & 9,7 & 6,1 & 8,6 & 13,1 \\
Mortalidade de crias (\%) & $27,3^{\mathrm{a}}$ & $8,8^{\mathrm{b}}$ & $17,9^{\mathrm{ab}}$ & $11,9^{\mathrm{a}}$ & $25,4^{\mathrm{b}}$ \\
Mortalidade de crias - parto duplo & $54,5^{\mathrm{a}}$ & $0^{\mathrm{b}}$ & $27,2^{\mathrm{ab}}$ & 20 & 38,8 \\
Mortalidade de crias -parto simples & 18,1 & 10,2 & 16,1 & 10,3 & 20 \\
Peso da cria ao nascimento $(\mathrm{Kg})$ & $3,09 \pm, 07^{\mathrm{b}}$ & $3,40 \pm 0,08^{\mathrm{a}}$ & $3,34 \pm 0,08^{\mathrm{a}}$ & $3,33 \pm 0,07$ & $3,22 \pm 0,06$ \\
\hline
\end{tabular}

$a, b$, Letras diferentes na mesma linha, para o mesmo efeito, indicam diferença significativa $(\mathrm{P}<0,05)$.

${ }^{1}$ Número de cordeiros nascidos/número ovelhas exposta * 100 .

${ }^{2}$ Número de cordeiros desmamados/número ovelhas exposta* 100

As ovelhas, independente do grupo, ganharam peso entre o início de cada ciclo até o parto e perderam entre o parto e o desmame. Somente entre o PI e o PM as ovelhas RS ganharam mais peso $(\mathrm{P}<0,05)$ que as RR (Tabela 1).

O grau de resistência à verminose não afetou as taxas de natalidade e de desmame mas diminuiu significativamente a mortalidade de ovelhas no grupo RR em relação ao grupo SS (Tabela 2). As mortes de ovelhas no grupo RR ocorreram exclusivamente no período do periparto-lactação e nos grupos RS e SS houve concentração nesse período.

A taxa de mortalidade de crias no grupo RS foi significativamente menor que no grupo SS e intermediária no grupo RR e foi influenciada, principalmente, pela mortalidade das crias de partos duplos. O PCN nos grupos RR e RS foram maiores que no grupo SS $(\mathrm{P}<0,05)$ (Tabela 2$)$. As interações entre grau de resistência, suplementação e sexo não foram significativas no PCN.

O grau de resistência aos nematodas tem produzido resultados divergentes quanto ao peso das ovelhas 
e das crias. Neste estudo, não houve efeito sobre a variação do peso corporal das ovelhas (Tabela 1) e o PCN das ovelhas RR e RS foram maiores que o das crias das ovelhas SS (Tabela 2). Kahn et al ${ }^{(29)}$ não observaram efeito do grau de resistência sobre o ganho de peso entre ovelhas resistentes e não selecionadas, mas observaram PCN mais elevado nos cordeiros nascidos de ovelhas não selecionadas. Greeff e Karlson ${ }^{(30)}$ observaram ganhos significativos no peso das ovelhas selecionadas para resistência; contudo, não observaram efeito no PCN.

Morris et al. ${ }^{(7)}$ observaram taxa de natalidade $11 \%$ maior em ovelhas resistentes (selecionadas por reprodução seletiva) quando comparadas às selecionadas para alto OPG; entretanto, os autores encontraram correlação genética desfavorável entre OPG e ganho de peso quando animais resistentes e sensíveis foram mantidos na mesma pastagem. Independentemente do grau de resistência, a concentração das mortes de ovelhas ocorreu no periparto-lactação (Tabela 2), fase caracterizada por aumento expressivo na exigência de proteína metabolizável ${ }^{(29)}$ e diminuição da resistência à verminose, coincidindo com o período de transição águas-seca, época de baixa disponibilidade e qualidade das pastagens na região (Figura 1 e Tabela 3).

A suplementação proteica no terço final da gestação e durante a lactação não influenciou as médias de OPG, o número de tratamentos anti-helmínticos e o percentual de aumento do OPG no periparto em relação ao período antecedente (Tabela 3). Sob o critério de aplicação de anti-helmíntico nos animais com $\mathrm{OPG} \geq \mathrm{a} 4000,51 \%$ dos tratamentos foram realizados nas ovelhas SUPL e 49\% nas NSUPL (Tabela 3).

O aumento do OPG no periparto tem sido relacionado à demanda nutricional das ovelhas, principalmente por proteína, no final da gestação e início da lactação ${ }^{(29,31)}$. Diversos trabalhos têm mostrado redução do OPG com a suplementação proteica no periparto ${ }^{(29,32-36)}$. Ovelhas natural ou experimentalmente infectadas e suplementadas com níveis de proteína abaixo do requerimento no final da gestação e inicio da lactação mostraram aumento do OPG no periparto maior que ovelhas suplementadas com níveis acima do requerimento ${ }^{(37-38)}$. Contudo, assim como neste estudo, Katiki et al. ${ }^{(39)}$ suplementaram ovelhas Santa Inês, Morada Nova e Texel no pós-parto com farelo de soja a $0,8 \%$ e $1,6 \%$ do peso vivo e não observaram efeito da dieta sobre o peso e o OPG.

Nas 30 coletas de fezes realizadas, a média de OPG das ovelhas RR estava menor que a média dos grupos SS e RS, exceto em uma coleta em relação ao grupo SS e em três coletas em relação ao grupo RS. A flutuação do OPG mostrou picos nos três grupos, iniciando no mês de nascimento das crias no primeiro ciclo e dois meses antes do nascimento no segundo ciclo (Figura 1).

Nos dois ciclos de estudo, a média de OPG no grupo RR foi inferior à do grupo SS e RS no período anterior ao periparto-lactação e semelhante entre os grupos RS e SS. No periparto, a média de OPG do grupo RR estava menor que a do grupo SS no primeiro ciclo e não houve diferença entre os grupos no segundo ciclo (Tabela 3). O aumento percentual da média de OPG verificado no período do periparto-lactação em relação ao período antecedente teve comportamento distinto entre os grupos (Tabela 3). Considerando os dois ciclos, no grupo SS a média de OPG no período do peripartolactação foi 2,5 vezes maior que no período antecedente, no grupo RS o aumento foi de 3,14 vezes e no grupo RR o aumento foi de 5,0 vezes. 

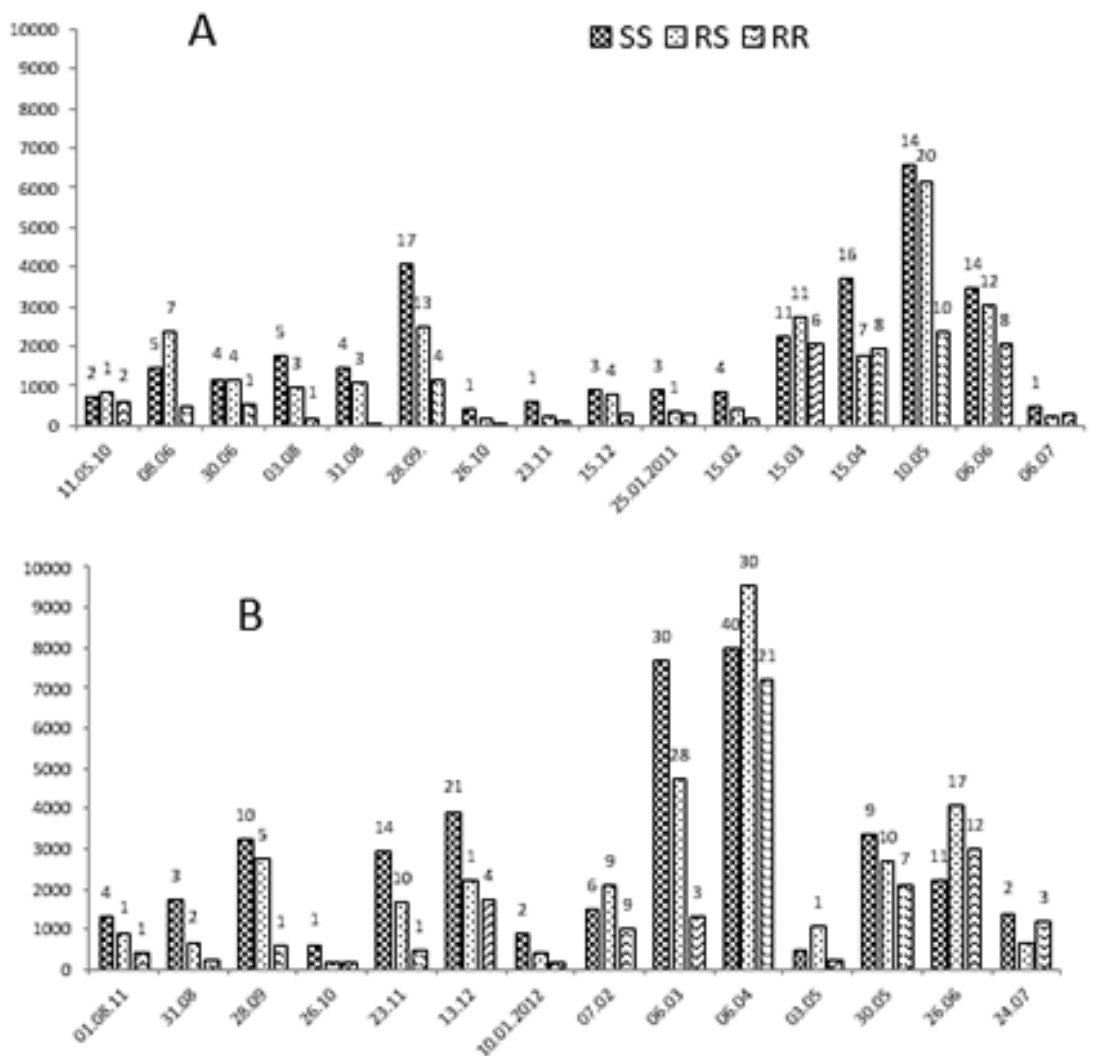

Figura 1. Médias de ovos de nematodas gastrintestinais por grama de fezes (OPG) e número de tratamentos anti-helmínticos (rótulo das médias) realizados em ovelhas classificadas com resistentes (RR), Sensiveis (SS) e Intermediárias (RS) no estado do Mato Grosso do Sul. Figura1A, primeiro ciclo experimental, Figura 1B, segundo ciclo experimental.

Tabela 3. Número de tratamentos anti-helminticos realizados (n), médias de OPG e percentual de aumento do OPG (\%) no periparto em ovelhas suplementadas (SUPL) e não (NSUPL) ou classificadas como resistentes (RR), intermediárias (RS) e sensiveis (SS) aos nematodas gastrintestinais

\begin{tabular}{ccccccc}
\hline \multicolumn{2}{c}{ Ciclo 1 } & & \multicolumn{3}{c}{ Ciclo 2 } \\
\hline & Antes do periparto & periparto & $\%$ & Antes do periparto & periparto & $\%$ \\
\hline SUPL & $(52) 979$ & $(76) 3517$ & 359 & $(55) 1343$ & $(108) 3008$ & 224 \\
NSUPL & $(42) 771$ & $(61) 2751$ & 357 & $(60) 1338$ & $(116) 3885$ & 290 \\
& & & & & & \\
RR & $(9) 354^{\mathrm{a}}$ & $(32) 2107^{\mathrm{a}}$ & 594 & $(16) 591^{\mathrm{a}}$ & $(46) 2498$ & 422 \\
RS & $(36) 984^{\mathrm{b}}$ & $(50) 3430^{\mathrm{b}}$ & 349 & $(38) 1368^{\mathrm{b}}$ & $(86) 3802$ & 278 \\
SS & $(49) 1295^{\mathrm{b}}$ & $(54) 4002^{\mathrm{b}}$ & 309 & $(61) 2010^{\mathrm{b}}$ & $(92) 3836$ & 191 \\
\hline
\end{tabular}

${ }^{2 b}$ Letras diferentes na mesma coluna indicam diferença significativa $(P<0,05)$.

Nos dois ciclos experimentais foram realizados 569 tratamentos anti-hemínticos, 230 no primeiro ciclo e 339 no segundo (Figura 1). Em ambos os ciclos, 45\% dos tratamentos foram realizados nas ovelhas SS, 37\% nas ovelhas RS e 18\% nas ovelhas RR. As médias de OPG do grupo RR, exceto no período do periparto, no segundo ciclo, foi significativamente menor que as do grupo SS, mesmo recebendo 2,5 vezes menos tratamentos anti-helmínticos (Tabela 3).

O aumento do OPG no periparto, mas com menor intensidade nas ovelhas resistentes (Figura 1) 
quando comparadas com ovelhas não selecionadas ou identificadas com alto OPG, já foi observado em estudos semelhantes ${ }^{(40-43)}$. O aumento percentualmente maior da média de OPG observado no grupo RR no período periparto-lactação em relação ao período antecedente pode ser atribuído ao uso mais intenso de tratamentos anti-helmínticos nos grupos SS e RS (Tabela 3). Rocha et al. ${ }^{(5)}$ acompanharam a flutuação do OPG durante o periparto em ovelhas Santa Inês (resistentes) e Ile de France e não observaram diferença no aumento do OPG, atribuindo o resultado ao maior número de tratamentos anti-helmínticos nas ovelhas Ile de France durante o período experimental. Basseto et al. ${ }^{(44)}$ observaram que ovelhas não prenhes, após classificação em sensíveis por exames seriados de OPG, tiveram média de OPG 4,1 vezes maior que as resistentes. Neste estudo, no período antecedente ao periparto, as diferenças entre as médias de OPG foram 3,4 a 3,6 vezes maiores no grupo SS em relação ao RR, mesmo recebendo 3,8 a 5,4 vezes mais tratamentos anti-helmínticos (Tabela 3).

A ausência de efeito desfavorável nas taxas de natalidade e de desmame, efeito favorável na taxa de mortalidade de ovelhas e no PCN e menor número de tratamentos anti-helmínticos nas ovelhas resistentes concordam com Amarante et al. ${ }^{(4)}$ e Rocha et al. ${ }^{(5)}$, que sugerem a possibilidade da utilização de indivíduos mais resistentes aos parasitas para elevar os índices zootécnicos dentro da ovinocultura.

Ovelhas resistentes contribuem, ainda, para a diminuição dos custos relacionados ao controle da verminose e da pressão de seleção para resistência dos nematodas aos anti-helmínticos. Nas 60 ovelhas resistentes, no período entre o desmame e o periparto, foram efetuados nove tratamentos antihelmínticos no primeiro ciclo e 16 tratamentos no segundo. A classificação das ovelhas para resistência com exames mensais consecutivos de OPG, permitiu diminuir o número de tratamentos anti-helmínticos e a mortalidade de ovelhas em $67 \%$ e $70 \%$, respectivamente. Contudo, para se fixar a característica de resistência no rebanho é necessário o uso de reprodutores que tenham sido selecionados com esse fenótipo.

\section{Conclusões}

A suplementação de ovelhas com ração concentrada no periparto-lactação, na quantia utilizada neste experimento, não teve influência no OPG e nos índices reprodutivos, mas reduziu a taxa de mortalidade das crias.

A classificação de ovelhas como resistentes à verminose com base no OPG diminuiu a mortalidade e o número de tratamentos anti-helmínticos nas ovelhas e produziu crias mais pesadas ao nascimento; no entanto, não influenciou na taxa de natalidade e de desmame.

\section{Agradecimentos}

Os autores agradecem à Fundação de Apoio ao Desenvolvimento do Ensino, Ciência e Tecnologia do Estado de Mato Grosso do Sul (FUNDECT) pelo apoio financeiro, e aos técnicos agrícolas e laboratoristas Marco Antonio da Silva e Ronaldo Luiz da Silva pelos trabalhos de campo e 
laboratório.

\section{Referências}

1. Carneiro LOHB. A ovinocultura de corte em Mato Grosso do Sul: uma alternativa econômica. Campo Grande, MS: Universidade Federal de Mato Grosso do Sul, 2002. 21p. (Monografia de Especialização em MBA).

2. Ribeiro LAO, Fontana CS, Wald VB, Gregory RM, Mattos RC. Relação entre a condição corporal e a idade das ovelhas no encarneiramento com a prenhez. Ciência Rural. 2003;33(2):357-36.

3. Sczesny-Moraes EA, Bianchin I, Silva KF, Catto JB, Honer M. R, Paiva F. Resistência anti-helmíntica de nematóides gastrintestinais em ovinos, Mato Grosso do Sul. Pesquisa Veterinária Brasileira. 2010;30(3):229236.

4. Amarante AFT, Bricarello PA, Rocha RA, Gennari SM. Resistance of Santa Ines, Suffolk and Ile de France lambs to naturally acquired gastrointestinal nematode infections. Veterinary Parasitology. 2004;120:91-106.

5. Rocha RA, Amarante AFT, Bricarello PA. Comparison of the susceptibility of Santa Inês and Ile de France ewes to nematode parasitism around parturition and during lactation. Small Ruminant Research. 2004;55(13):65-75.

6. Liu SM, Smith TL, Karlsson LJE, Palmer DG, Besier RB. The costs for protein and energy requirements by nematode infection and resistance in Merino sheep. Livestock Production Science. 2005;97(2-3):131-139.

7. Morris CA, Vlassoff A, Bisset SA, Baker RL, Watson TG, West C J,Wheeler M. Continued selection of Romney sheep for resistance or susceptibility to nematode infection: estimates of direct and correlated responses. Journal Animal Science. 2000;70(1):17-27.

8. Greer AW. Trade-offs and benefits: implications of promoting a Strong immunity to gastrointestinal parasites in sheep. Parasite immunology. 2008;30:123-132.

9. Sykes AR. Host immune responses to nematodes: benefit or cost? Implications forfuture development of sustainable methods of control. Revista Brasileira de Zootecnia. 2010;39:376-382.

10. Crispin BA, Grisolia AB, Seno LO, Egito AA, Vargas Junior FM, Souza MR. Genetic diversity of locally adapted sheep from Pantanal region of Mato Grosso do Sul. Genetics and Molecular Research. 2013;12(4):5458-5466.

11. Gomes WS, Araújo AR, Caetano AR, Martins CF, Vargas Jr, FM, McManus CM, Paiva SR. Origem e diversidade genética da ovelha crioula do Pantanal, Brasil. In: Simpósio de Recursos Genéticos para América Latina y el Caribe, 6., Cidade do México. Memoria.Chapingo: México, Universidad Autonoma Chapingo, 2007. p. 322.

12. Vargas-Junior FM, Martins CF, Souza CC, Pinto GS, Pereira HF, Camilo FR, Azevedo Júnior NP. de. Avaliação Biométrica de Cordeiros Pantaneiros. Revista Agrarian. 2011;4(11):60-65.

13. Ferreira MB, Fernandes LH, Carmona R. Ovelha Pantaneira: uma nova raça de animais com 300 anos de história. Rev. Cabra \& Ovelha, n. 72, 2012, Disponível em: http://www.cabraeovelha.com.br/website/Edicoes.php?e=72\&c=728\&d=0.Acesso: março/10/2013.

14. MANEJOS REPRODUTIVOS. Sistemas de acasalamento x Sincronização de cio - Pequenos Ruminantes. Disponível em: http://www.tecnopec.com.br/download.php?f=1e463475af46ce6399c6f65df34c3538>. Acessado em: 16/08/2010.

15. Whitlock HV. Some modifications of the McMaster helminth egg -counting technique and apparatus. Journal Coun. Sci. Ind. Research, Austrália. 1948;21:177-180. 
16. Amarante AFT, Craig TM, Ramsey WS, Sayed NME, Desouki AY, Bazer FW. Comparison of naturally acquired parasite burdens among Florida Native, Rambouillet and crossbred ewes. Veterinary Parasitology. 1999;85:61-69.

17. NRC. Nutrient Requirements of Small Ruminants: Sheep, Goats, Cervids, and New World Camelids National Academy of Science, Washintgton, D.C. 2007. 347p.

18. Figueiredo E A P. de; Oliveira E R de; Bellaver C. Performance dos ovinos deslanados no Brasil. Sobral: EMBRAPA-CNPC, 1980.32 p. (Circular Técnica, 1). Disponível em http://ainfo.cnptia.embrapa.br/digital/bitstream/item/36455/1/CT-01.pdf, acesso em maio 2017.

19. Ximenes LJF, Oliveira SMP, Vilarroel ABS, Bozzi R. Características reprodutivas de ovelhas deslanadas SRD no Ceará. In: REUNIÃO ANUAL DA SOCIEDADE BRASILEIRA DE ZOOTECNIA, 41., 2004, Campo Grande. Anais... Campo Grande - MS: Embrapa, CNGC, 2004. Disponível em http://www.sbz.org.br/reuniaoanual/anais/arq_reuniao_anual/sbz2004.rar.

20. Moura ABC. Desempenho reprodutivo de ovelhas Santa Inês criadas no nordeste paraense. 2009. 64 f. Dissertação (Mestrado em Zootecnia) - Universidade Federal do Ceará, Fortaleza, 2009. Disponível em http://ivros01.livrosgratis.com.br/cp108776.pdf, acesso em maio 2017.

21. Figueiredo EAP.. Potencial breeding plans developed from observed genetic parameter and simulated genotypes for Morada Nova sheep in Northeast Brazil. Texas A. \& M University. 165p. 1986.

22. Costa MJR. da, Queiroz SA de, Ribeiro JLC. Avaliação de alguns aspectos do desempenho de ovinos da raça Morada Nova na região de Franca - SP. Revista da Sociedade Brasileira de Zootecnia. 1990;19(4).

23. Mexia AA, Macedo FAF, Alcade CR, Zakaguti ES, Martins EN, Zundt M, et al. Desempenhos reprodutivo e produtivo de ovelhas Santa Inês suplementadas em diferentes fases da gestação. Revista da Sociedade Brasileira de Zootecnia. 2004;33(3):658-667.

24. Silva FLR, Araújo AM, Figueiredo EAP. Características de crescimento e de reprodução em ovinos somalis no nordeste brasileiro. Revista Brasileira de Zootecnia. 1998;27(6):1107-1114.

25. Rajab MH, Cartwright TC, Dahm PF, Figueiredo EA. Performance of three tropical hair sheep breeds. Journal Animal Science. 1992;70((11):3351-3359.

26. Pinheiro JHT. Parâmetros Reprodutivos de Ovelhas da Raça Santa Inês Criadas no Sertão do Ceará. 2004. 53 f. Dissertação (Mestrado em Ciências Veterinárias) - Faculdade de Veterinária, Universidade Estadual do Ceará, Fortaleza, 2004. Disponível em http://www.uece.br/ppgcv/dmdocuments/joaquim_pinheiro.pdf, acesso em maio 2017.

27. Silva AEDF, Unanian MM, Barros NN. Efeito da suplementação no desempenho produtivo e reprodutivo de ovelhas deslanadas no Nordeste. Pesquisa Agropecuária Brasileira. 1986;21(9):987-997.

28. Moura Filho J, Ribeiro ELA, Silva LDF, Rocha MA, Mizubuti IY, Pereira S, Mori RM. Suplementação alimentar de ovelhas no terço final de gestação: desempenho de ovelhas e cordeiros até o desmame. Semina. Ciências Agrárias. 2005;26(2):257-266.

29. Kahn LP, Knox MR, Gray GD, Lea JM, Walkden-Brown SW. Enhancing immunity to nematode parasites in single-bearing Merino ewes through nutrition and genetic selection. Veterinary Parasitology. 2003;112:211225.

30. Greef J, Karlsson LJE. Breeding for worm resistance- whole farm benefits. International Journal of Sheep and Wool Science. 2006;54(2):102-108.

31. Coop RL, Kyriazakis I. Influence of host nutrition on the development and consequences of nematode parasitism in ruminants. Trends in Parasitology.2001;17(7):325-330.

32, Houdijk JGM, Kyriazakis I, Jackson F, Coop RL. The relationship between protein nutrition, reproductive effort and breakdown in immunity to Teladorsagia circumcincta in periparturient ewes. Animal Science. 
2001;72:595-606.

33 Zaralis K, Tolkamp BJ, Houdijk JGM, Alastair RGW, Kyriazakis I. Consequences of protein supplementation for anorexia, expression of immunity and plasma leptin concentrations in parasitized ewes of two breeds. British Journal of Nutrition. 2008;101(4):499-509.

34. Kidane A, Houdijk JGM, Tolkamp BJ, Athanasiadou S, Kyriazakis I. Consequences of infection pressure and protein nutrition on periparturient resistance to Teladorsagia circumcincta and performance in ewes. Veterinary Parasitology. 2009;165:78-87.

35. Kidane A, Houdijk J, Athanasiadou S, Tolkamp B, Kyriazakis I. Nutritional sensitivity of periparturient resistance to nematode parasites in two breeds of sheep with different nutrient demands. British Journal of Nutrition. 2010;104:1477-1486.

36. Beasley AM, Kahn LP, Windon RG. The influence of reproductive physiology and nutrient supply on the periparturient relaxation of immunity to the gastrointestinal nematode Trichostrongylus colubriformis in Merino ewes. Veterinary Parasitology. 2012;188(3-4):306-324.

37. Houdijk JGM, Kyriazakis I, Jackson F, Huntley JF, Coop RL. Can an increased intake of metabolizable protein affect the periparturient relaxation in immunity against Teladorsagia circumcincta in sheep. Veterinary Parasitology. 2000;91:43-62.

38. Sykes AR, Xie HL, Stankiewicz M, Huntley JF, Mackellar A, Sedcole JR, et al. The effect of vaccinating infection during pregnancy and dietary protein supply on the peri-parturient immune response of sheep to infection with Teladorsagia circumcincta and Trichostrongylus colubriformis larvae. Animal. 2007;1:249260 .

39. Katiki LM, Veríssimo C, Bueno JMS, Cunha EA, Santos LE, Otsuk IP. Infecção por nematódeos gastrintestinais no período pós-parto, em ovelhas das raças santa inês, morada nova e texel suplementadas com dois níveis de proteína na dieta. Biológico. 2006;68:213-217.

40. Woolaston RR. Selection of Merino sheep for increased and decreased resistance to Haemonchus contortus: Peri-parturient effects on faecal egg counts. International Journal for Parasitology.1992;22(7):947_ 953.

41. Morris CA, Bisset AS, Vlassoff A, West CJ, Wheeler M. Faecal nematode egg counts in lactating ewes from Romney flocks selectively bed for divergence in lamb faecal egg count. Animal Science. 1998;67:283288.

42. Karlsson LJE, Greeff JC. Selection response in fecal worm egg counts in the Rylington Merino parasite resistant flock. Australian Journal of Experimental Agriculture. 2006;46:809-811.

43. Williams AR, Greeff JC, Vercoe PE, Dobson RJ, Karlsson LJE. Merino ewes bred for parasite resistance reduce larval contamination onto pasture during the peri-parturient period. Animal. 2010;4(1):122-127.

44. Bassetto CC, Silva BF, Fernandes S, Amarante AFT. Contaminação da pastagem com larvas infectantes de nematoides gastrintestinais após o pastejo de ovelhas resistentes ou susceptíveis à verminose. Revista Brasileira de Parasitologia veterinária. 2009;18(4):63-68. 